\title{
First Web-space Reconstruction Using the Second Dorsal Metacarpal Artery Cutaneous Flap: A Reliable Choice for Large Defects
}

\section{Heng Tian \\ Jilin University \\ Wenlai Guo \\ Jilin University \\ Qinghe Han \\ Jilin University \\ Quanzhe Liu \\ Jilin University \\ Lei Zhang \\ Jilin University}

Wenrui Qu ( $\nabla$ quwenrui@jlu.edu.cn )

The Second Hospital of Jilin University https://orcid.org/0000-0002-0178-3698

Rui Li

Jilin University

\section{Research}

Keywords: dorsal metacarpal artery, distal cutaneous branch of the second dorsal metacarpal artery, first web-space, reconstruction, defect

Posted Date: July 15th, 2020

DOI: https://doi.org/10.21203/rs.3.rs-41245/v1

License: (c) (i) This work is licensed under a Creative Commons Attribution 4.0 International License. Read Full License 


\section{Abstract \\ Background}

First web-space defect reconstruction is challenging for reconstructive surgeons. The second dorsal metacarpal artery (SDMA) flap is useful in treating hand and finger defects. However, limited studies have used it for the first web-space defects. This study reports a modified SDMA flap to treat first web-space softtissue defects.

\section{Methods}

From April 2012 to October 2018, 8 patients underwent a modified SDMA flap transfer (mean flap size, $2 \times$ $3 \mathrm{~cm}$ to $4 \times 6 \mathrm{~cm}$ ). The average length of the pedicle was $2.9 \mathrm{~cm}$. On average, the flap was rotated $84^{\circ}$. In 6 patients, full-thickness skin was grafted at the donor sites. The donor site was primarily closed in two cases.

\section{Results}

All wounds were healed without complications of flap failure or donor area-related morbidity. The average follow-up period was 7.9 months, and these patients were satisfied with the functional recovery and cosmetic appearance of the scar area. At the end of follow-up, the average movement range of the metacarpophalangeal joint of the thumb, index finger, and long finger were $84^{\circ}, 88^{\circ}$, and $87^{\circ}$, respectively, while those of the contralateral thumb, index finger, and long finger were $87^{\circ}, 88^{\circ}$, and $85^{\circ}$, respectively. The first web of the injured side spanned an average of $73^{\circ}$; the measurement on the contralateral side was $91^{\circ}$.

\section{Conclusions}

The SDMA flap reconstruction is a simple and fast procedure with a wide resurfacing range for large first web-space defects, low donor-site morbidity, and good functional and esthetic appearance.

\section{Background}

An adequate first web-space is required to maintain normal hand functions such as pinching, gripping, and prehension. Owing to its importance in hand movements, it is important to maintain the mobility of the first web-space and prevent or minimize its contracture $(1,2)$. First web-space defects can be treated with various reconstructive methods, including the dorsal metacarpal flap, posterior interosseous forearm flap, reversed flow radial forearm flaps, reversed ulnar forearm flap, microsurgical anterolateral thigh flap, and skeletal traction(3). Z-plasty and local flaps based on hand alone are ineffective in rebuilding large defects. Although skin grafts can cover most of the web-space defects, they cannot improve the functional aspect or produce a stable outcome. Moreover, contracture recurrence is often observed, which may necessitate a second surgery. 
A variety of local flaps has been reported to reconstruct web-space defects. However, they are inadequate to treat extremely large or deep defects. The posterior interosseous artery flap could be an alternative, but it is bulky, requires skin grafting, and leaves noticeable scars, which cannot be easily covered(3). Free and remote flaps have also been recommended to reconstruct the soft-tissue defects of the web-space. However, these procedures require longer operating time, demand microsurgical expertise, and have the risk of anastomosis failure.

Pedicled flaps have remained significant in reconstructive first web-space surgeries as they follow the basic concept of "like-with-like." In 1987, Earley, for the first time, reported the usefulness of the second dorsal metacarpal artery (SDMA) flap for the treatment of first web-space contractures(4). Several modified SDMA island flaps have been described since. Quaba et al. reported the usefulness of a distally based dorsal metacarpal artery perforator flap for resurfacing web-space defects(5). Recent studies have reported the presence of additional communication arterial networks in the web-space and proximal phalanx, thereby providing newer options for flap design(6-9).

SDMA flaps have been extensively used for treating hand and finger defects(10-13). The SDMA flap has sufficient and stable blood supply, a broad rotational arc, and low morbidity in the donor site. However, to our knowledge, limited studies have previously reported the use of SDMA flap to reconstruct large defects. It is reasonable to assume that the limited flap width restricts its use for extensive defects involving the first webspace. Wang et al. reported the presence of transverse arterial communication networks among neighboring cutaneous branches of the dorsal metacarpal arteries(14), indicating that a modified flap may be designed based on transverse and axial arterial networks, extending beyond the adjacent metacarpal arteries. Significant advances have been made in identifying the arterial networks of SDMA, and many studies have reported promising results that could increase the width and length of the SDMA flap to improve, thereby improving the therapeutic strategies for restoring large defects of the hand. Based on the above-mentioned studies, the authors describe a novel, modified design of the SDMA flap for first web-space defects reconstruction.

\section{Methods}

From April 2012 to October 2018, a modified SDMA flap transfer was performed in 8 hands of 8 patients (5 men and three women). The etiologies of injury were degloving $(n=1)$, burn $(n=1)$, avulsion $(n=4)$, and crush $(n=2)$. All cases of web-space defects were reconstructed with SDMA flaps. The demographic and surgical details of the patient are summarized (Table. 1). The study was approved under the ethical committees of the hospitals. All clinical investigations were conducted in accordance with the principles expressed in the Declaration of Helsinki.

Tab.1 Demographic and surgical details of the patient. M, male; F, female 


\begin{tabular}{|c|c|c|c|c|c|c|c|c|c|}
\hline Patient & $\begin{array}{l}\text { Age } \\
\text { (yr) }\end{array}$ & Sex & Cause & $\begin{array}{l}\text { Flap } \\
\text { Size } \\
(\mathrm{cm})\end{array}$ & $\begin{array}{l}\text { Pedicle } \\
\text { length } \\
(\mathrm{cm})\end{array}$ & $\begin{array}{l}\text { Rotation } \\
\text { (degree) }\end{array}$ & $\begin{array}{l}\text { Donor } \\
\text { site }\end{array}$ & $\begin{array}{l}\text { Follow- } \\
\text { up }\end{array}$ & Complications \\
\hline 1 & 26 & $M$ & Degloving & $\begin{array}{l}4 \times \\
2.7\end{array}$ & 3 & 85 & $\begin{array}{l}\text { Skin } \\
\text { graft }\end{array}$ & 12 & None \\
\hline 2 & 53 & $\mathrm{~F}$ & Burn & $\begin{array}{l}2 x \\
3\end{array}$ & 3.3 & 75 & $\begin{array}{l}\text { Direct } \\
\text { closure }\end{array}$ & 8 & None \\
\hline 3 & 38 & $\mathrm{~F}$ & Avulsion & $\begin{array}{l}3.7 \\
\times \\
2.9\end{array}$ & 2.9 & 85 & $\begin{array}{l}\text { Direct } \\
\text { closure }\end{array}$ & 7 & None \\
\hline 4 & 39 & $\mathrm{~F}$ & Crush & $\begin{array}{l}4.1 \\
\times \\
2.6\end{array}$ & 3.2 & 90 & $\begin{array}{l}\text { Skin } \\
\text { graft }\end{array}$ & 10 & None \\
\hline 5 & 41 & $M$ & Avulsion & $\begin{array}{l}4.6 \\
\times \\
3.2\end{array}$ & 2.6 & 90 & $\begin{array}{l}\text { Skin } \\
\text { graft }\end{array}$ & 6 & None \\
\hline 6 & 37 & $M$ & Avulsion & $\begin{array}{l}3.5 \\
\times \\
4.8\end{array}$ & 2.5 & 75 & $\begin{array}{l}\text { Skin } \\
\text { graft }\end{array}$ & 6 & None \\
\hline 7 & 48 & $M$ & Crush & $\begin{array}{l}4 \times \\
6\end{array}$ & 2.8 & 90 & $\begin{array}{l}\text { Skin } \\
\text { graft }\end{array}$ & 10 & None \\
\hline 8 & 59 & $M$ & Avulsion & $\begin{array}{l}3.2 \\
\times \\
4.2\end{array}$ & 3 & 80 & $\begin{array}{l}\text { Skin } \\
\text { graft }\end{array}$ & 4 & None \\
\hline
\end{tabular}

\section{Operative technique}

Under plexus block or general anesthesia, the patient was placed in a supine position. A Doppler ultrasound was performed to assess the SDMA and locate the pedicle position. The acute wounds were debrided, and the skin flap was outlined according to the area of the recipient site. At approximately $1.0 \mathrm{~cm}$ close to the second metacarpophalangeal (MCP) joint, Doppler ultrasound was used to detect SDMA bifurcation and its distal dermal branch. The pedicle was positioned along the distal cutaneous branch of the SDMA, which flows proximally between the first and third metacarpals. The initial incision was cut along the margin of the flap. The maximum flap size included the dorsal skin of the MCP and carpometacarpal joints, and that between the marginal lines of the first and fourth metacarpals (Fig. 1). The edges of the flap were incised and elevated from the proximal to the distal direction in the subcutaneous plane. The pedicle, along with the subcutaneous tissue, was dissected distally between the second and third metacarpals. The cutaneous branch of the SDMA close to the pivotal point was also ligated or transected to ensure continuity of the cutaneous branch(Fig. 2). 
After surgical debridement, the flap was rotated to the recipient site through an open incision or a subcutaneous tunnel. The donor site was primarily closed or resurfaced with skin grafting. Postoperatively, the flap was monitored visually for seven days to assess tissue color and capillary refilling. The thumb was immobilized postoperatively for 12-14 days with a protective splint.

\section{Outcome evaluation}

At the end of follow-up (range, 4-12 months), the range of motion (ROM) of the hand was measured three times using a goniometer, and the mean value was calculated. Web span was measured with the thumb and fingers in maximal abduction. These measurements were compared to those obtained for the contralateral hand. Postoperative scar pain at the donor sites and the first web-space were assessed using a visual analogue scale (VAS; a 10-cm horizontal line). Hand appearance and function were assessed by a single assessor using the Michigan Hand Outcome Questionnaire.

\section{Results}

The mean age of the patients at flap transfer was 42.6 years (range, 26-59 years) old. The flap sizes ranged from $2 \mathrm{~cm} \times 3 \mathrm{~cm}$ to $4 \mathrm{~cm} \times 6 \mathrm{~cm}$, and the mean pedicle length was $2.9 \mathrm{~cm}$ (range, 2.5-3.3 cm). The flaps were rotated by an average of $84^{\circ}$ (range, $75-90^{\circ}$ ). In 6 cases, the donor area was grafted with a fullthickness skin graft, while the donor site was primarily closed in two cases.

The wounds in all patients healed uneventfully and without any flap complications, such as arterial insufficiency or venous congestion. No patient manifested any apparent donor site-related morbidity. The mean follow-up period was 7.9 months (range, 4-12 months), and all the patients were satisfied with the postoperative functional outcomes and the appearance of the donor site scars.

At the final follow-up, the average ROMs of the MCP joint of the thumb, index finger, and long finger were $84^{\circ}$, $88^{\circ}$, and $87^{\circ}$, respectively; those of the contralateral thumb, index finger, and long finger were $87^{\circ}, 88^{\circ}$, and $85^{\circ}$, respectively. The average span of the first web on the injured side was $73^{\circ}$, while that on the contralateral side was $91^{\circ}$ (Table 2). 
Table 2

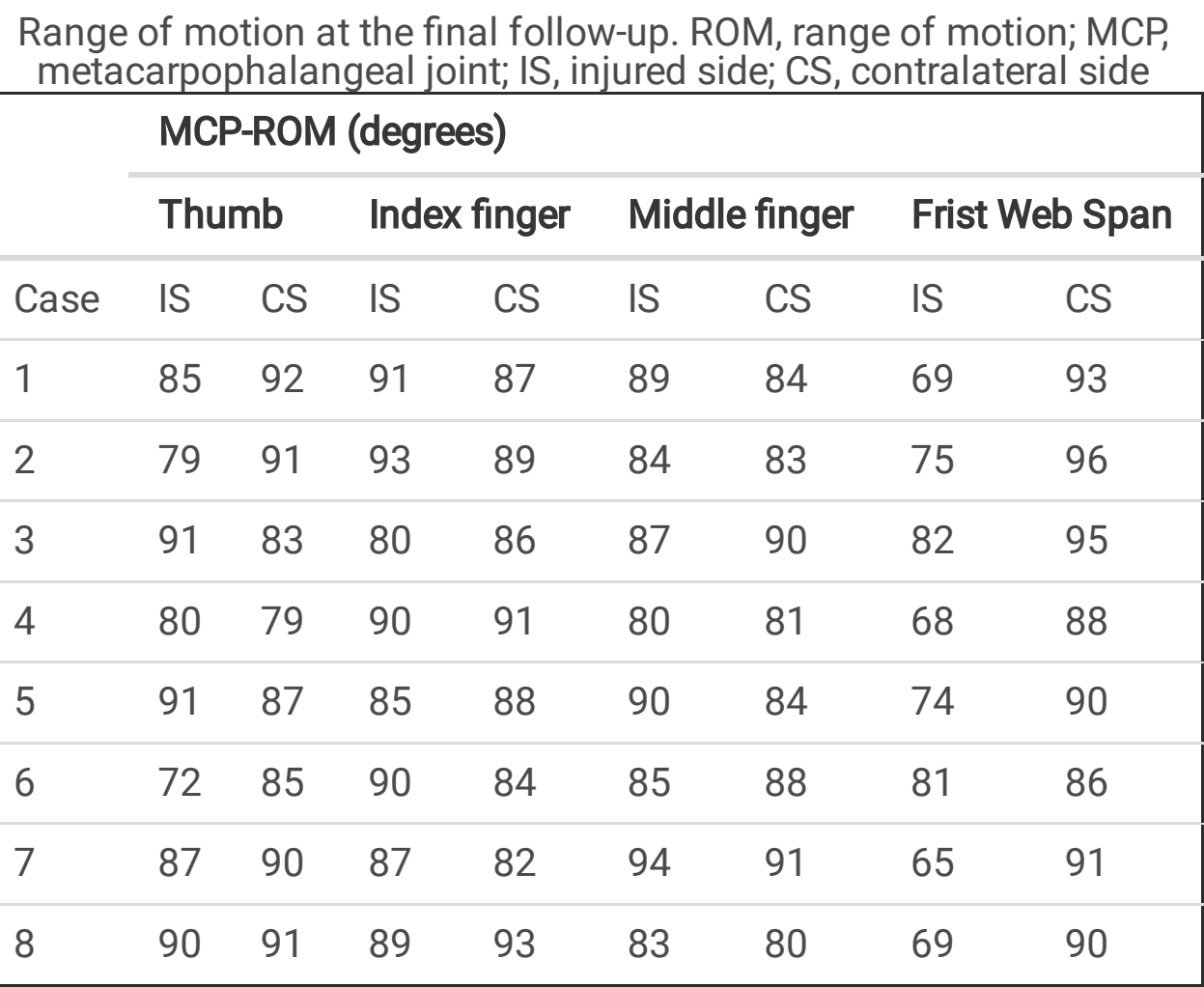

The results of postoperative pain assessment by VAS showed that only one patient reported pain at the first web-space (VAS score, 2). No patient reported scar pain at the donor site. Seven patients were satisfied with the aesthetic result of the flap and donor site of the hands according to the outcomes of the Michigan Hand Outcome Questionnaire. One patient experienced occasional discomfort with their hand appearance. All the patients were satisfied with both the ROM of fingers and hand strength.

\section{Case 1}

A 37-year-old woman was hospitalized after an avulsion injury of the first web-space of her left hand (Fig. 3). After surgical debridement, a pedicled SDMA flap $(3.5 \mathrm{~cm} \times 4.8 \mathrm{~cm})$ was dissected in a proximal-to-distal direction, rotated by $75^{\circ}$, and then rotated to cover to the injury site via a subcutaneous tunnel for first webspace reconstruction. The mean pedicle length was $2.5 \mathrm{~cm}$. A full-thickness skin transplantation was conducted on the donor area (Fig. 4). Postoperatively, the wounds healed uneventfully, with complete flap survival. Results at postoperative 6-month follow-up indicated an aesthetic result of the flap (Fig. 5).

\section{Case 2}

A 48-year-old man was admitted to our hospital due to a crush injury. A $3.5 \times 5.5-\mathrm{cm}$ defect remained after wound debridement, for which a free lateral arm flap was initially planned. However, the flap failed, presumably because of arterial thrombosis. Therefore, a $4 \times 6-\mathrm{cm}$ salvage SDMA cutaneous flap was designed. The flap was rotated $90^{\circ}$ to resurface the first web defect (Fig. 6). Thereafter, the skin harvested from the lost flap was grafted to the dorsum of the hand. The patient had an uneventful postoperative recovery without venous congestion, infection, or necrosis of the flap. Follow-up assessment at postoperative two months demonstrated an excellent result, with an improvement of the esthetic 
appearance. ROMs of the thumb, index, and long fingers of the injured hand were comparable to those of the contralateral hand. The patient's postoperative pain score was 0 on VAS, and he was fully satisfied with the outcome (Fig. 7).

\section{Discussion}

First web-space defect-a common sequela of hand trauma-can be caused by injuries, burns, paralysis, and infection. This defect has a profound adverse effect on the hand function, as even a slight contracture will result in decreased thumb mobility. The present study investigated the usefulness and postoperative outcomes of a novel, modified SDMA flap technique to treat first web-space soft-tissue defects in eight patients. This modified technique conferred good postoperative outcomes and an acceptable esthetic appearance. The donor area was closed directly in two cases, while those in six cases were resurfaced with skin grafting. The modified SDMA flap technique is timesaving, without causing any flap loss. Moreover, neither flap necrosis nor a web contracture was seen.

When selecting donor sites for the reconstruction of the web-space, the hand itself is preferable to other sites due to various advantages, including "like-with-like" tissues, superior recovery of sensitivity, and the requirement for a limited surgical area in a single anatomic region. Therefore, pedicled flaps remain important in reconstructive first web-space surgeries. The first dorsal metacarpal artery flap was commonly used for web-space defects $(15,16)$. Doğan described new bio-geometric designs of first dorsal metacarpal artery flap-bilobed or V-Y advancement flap-to reconstruct soft-tissue defects of the first web-space and the proximal dorsal thumb(17). This technique is generally indicated for complex defects. The contraindications of this technique include overlapped injuries to the donor region or to the pathway of the first dorsal metacarpal artery. The first dorsal metacarpal artery flap is also limited by the small size (up to $4 \mathrm{~cm}$ ), which may not be large enough to cover most of its hand defects(18). Zhang et al. described the use of the SDMA flap to repair thumb defects. The flap sizes ranged from $3.5 \mathrm{~cm} \times 3 \mathrm{~cm}$ to $3 \mathrm{~cm} \times 3.5 \mathrm{~cm}(19)$. If the flap goes beyond the proximal interphalangeal joint, the flap survival may not be reliable. This technique is more suitable for the coverage of small-sized web-space defects. Zhu reported the use of bilobed SDMAbased island flap for the reconstruction of complex soft-tissue defects around the MCP joint of the thumb, which was harvested from both the index and long fingers(20). The average size of the flaps from the index and long fingers was $2.6 \mathrm{~cm} \times 3.4 \mathrm{~cm}$ and $2.8 \mathrm{~cm} \times 3.2 \mathrm{~cm}$, respectively. However, the disadvantages include a relatively complicated procedure and partial sensory impairment at the donor fingers.

To our knowledge, only a few studies have previously reported the use of SDMA flap to cover first web-space defects. Presumably, the limited flap width may restrict its use for larger defects involving the first webspace. However, our technique could offer a reliable chance for the reconstruction of the first web-space defects. The flap margins were outlined proximally and distally to preserve the dorsal skin of the MCP and carpometacarpal joints, respectively, and between the marginal lines of the first and fourth metacarpals. The cutaneous perforators of the SDMA have consistent ascending and descending branches. The adjacent ascending branches were anastomosed with the adjacent descending branches to form the axis of the cutaneous chain, which was parallel to the $\operatorname{SDMA}(14,21)$. Notably, there is a consistent anastomosis between the dorsal metacarpal arteries to form the transverse arterial network. Usually, the flap pedicle is 
sufficiently wide to cover the recipient area without any tension(14). In this study, $4 \times 6-\mathrm{cm}$ flaps were harvested. Moreover, the flaps were narrowly rotated (by over $90^{\circ}$ ) to cover the web-space defect and to reduce the risk of venous insufficiency. This flap is reliable and versatile, simple and fast, has low donor site morbidity, and provides acceptance appearance cosmetically.

The advantages of this technique are the extended flap length and width, small rotation, low donor site morbidity, appropriate flap thickness, a low rate of flap failure, and almost near-physiological skin texture at the recipient area. Moreover, postoperatively, during the follow-up period, the patients' thumbs had the freedom of movement in any direction, and there were no sensorial complaints of the resurfaced anatomical parts. However, our study had a limited number of patients to assess the effectiveness of our flaps.

\section{Conclusion}

In conclusion, our modified SDMA flap is a simple and fast procedure with a wide resurfacing range for large first web-space defects, low donor site morbidity, and good functional and esthetic results. Moreover, the flap pedicle was sufficiently wide to reach the first web-space without any tension. Thus, the SDMA flap technique could offer a reliable chance for the reconstruction of first web-space defects.

\section{Abbreviations}

SDMA: second dorsal metacarpal artery; ROM: range of motion

\section{Declarations}

\section{Availability of data and materials}

Not applicable

\section{Ethics approval and consent to participate}

Not applicable

\section{Consent for publication}

Informed consent was required and obtained from the participants.

\section{Conflicts of interest}

The authors declared that they have no conflicts of interest in this work.

\section{Funding}

Not applicable 


\section{Authors' contributions}

HT designed the study; WG and QH outlined the manuscript; QL and LZ provided a detailed guidance throughout the article. WQ reviewed the manuscript. All the author read and approved the final manuscript.

\section{Acknowledgments}

Not applicable

\section{References}

1. Moody L, Galvez MG, Chang J. Reconstruction of First Web Space Contractures. Journal of Hand Surgery. 2015;40(9):1892-5.

2. Yuan F, Zhong L, Chung KC. Aesthetic Comparison of Two Different Types of Web-Space Reconstruction for Finger Syndactyly. Plastic and Reconstructive Surgery. 2018;142(4).

3. Zhang YX, Qian Y, Pu Z, Ong YS, Messmer C, Li Q, et al. Reverse Bipaddle Posterior Interosseous Artery Perforator Flap. Plastic and Reconstructive Surgery. 2013;131(4).

4. Earley MJ. The second dorsal metacarpal artery neurovascular island flap. The Journal of Hand Surgery: British European Volume. 1989;14(4):434-40.

5. Quaba A, Davison P. The distally-based dorsal hand flap. Br J Plast Surg. 1990;43(1):28-39.

6. Chi Z, Lin D, Chen Y, Xue J, Li S, Chu T, et al. Routine closure of the donor site with a second dorsal metacarpal artery flap to avoid the use of a skin graft after harvest of a first dorsal metacarpal artery flap. Journal of Plastic Reconstructive Aesthetic Surgery. 2018;71(6):870-5.

7. Couceiro J, Red-Gallego MDI, Yeste L, Ayala H, Sanchez-Crespo M, Velez O, et al. The Bilobed Racquet Flap or Extended Seagull Flap for Thumb Reconstruction: A Case Report. The Journal of Hand Surgery (Asian-Pacific Volume). 2018;23(01):128-31.

8. Al-Baz T, Gad S, Keshk T, Aly M. Evaluation of dorsal metacarpal artery perforator flaps in the reconstruction of hand soft-tissue defects. Menoufia Medical Journal. 2019;32(4):1256-61.

9. Webster N, Saint-Cyr M. Flaps Based on the Dorsal Metacarpal Artery. Hand Clin. 2020;36(1):75-83.

10. Perera NK, Rozen WM, Niumsawatt V, Ek E. First web space reconstruction using a dorsal metacarpal artery perforator flap: a further application of the Quaba flap. Plastic reconstructive surgery. 2014;133(1):74e-6e.

11. Zhang X, Shao X, Ren C, Wen S, Zhu H, Sun J. Coverage of Dorsal-Ulnar Hand Wounds with a Reverse Second Dorsal Metacarpal Artery Flap. J Reconstr Microsurg. 2012;28(03):167-74.

12. Zhang X, Shao X, Ren C, Zhang Z, Wen S, Sun J. Reconstruction of Thumb Pulp Defects Using a Modified Kite Flap. Journal of Hand Surgery. 2011;36(10):1597-603.

13. Sebastin SJ, Mendoza RT, Chong AKS, Peng YP, Ono S, Chung KC, et al. Application of the Dorsal Metacarpal Artery Perforator Flap for Resurfacing Soft-Tissue Defects Proximal to the Fingertip. Plastic and Reconstructive Surgery. 2011;128(3). 
14. Wang Z-t, Zhu L, Li C. Use T shape flap based dorsal metacarpal artery cutaneous branch to repair the ring form tissue defect of finger. Chinese Journal of Microsurgery. 2008;31(1):12-4.

15. Wang H, Chen C, Li J, Yang X, Zhang H, Wang Z. Modified first dorsal metacarpal artery island flap for sensory reconstruction of thumb pulp defects. Journal of Hand Surgery (European Volume). 2016;41(2):177-84.

16. Feng S-M, Sun Q-Q, Cheng J, Wang A-G, Li C-K. Superficial Radial Nerve Transection Improves Sensory Outcomes in First Dorsal Metacarpal Artery Flaps. Plast Reconstr Surg. 2017;140(3):558-64.

17. Doğan F, Çoruh A. Novel Biogeometric Designs of First Dorsal Metacarpal Artery Flap in Hand Reconstruction. Journal of Burn Care Research. 2014;35(6):e399-405.

18. Zhang X, Shao X, Shen Q, Yu Y, Li Y, Fan A. Use of the First Dorsal Metacarpal Artery-Based Fascial Flap for Reconstruction of Small Defects on the Dorsum of the Hands. Journal of Hand Surgery. 2019;44(12):1096. .e1-.e6.

19. Zhang X, He Y, Shao X, Li Y, Wen S, Zhu H. Second Dorsal Metacarpal Artery Flap From the Dorsum of the Middle Finger for Coverage of Volar Thumb Defect. The Journal of Hand Surgery. 2009;34(8):146773.

20. Zhu H, Zhang X, Yan M, Sheng Q, Wen S, Ren C. Treatment of Complex Soft-Tissue Defects at the Metacarpophalangeal Joint of the Thumb Using the Bilobed Second Dorsal Metacarpal Artery-Based Island Flap. Plast Reconstr Surg. 2013;131(5):1091-7.

21. Liu P, Qin X, Zhang H, Sun C, Zheng Y, Xu Y, et al. The second dorsal metacarpal artery chain-link flap: an anatomical study and a case report. Surg Radiol Anat. 2015;37(4):349-56.

\section{Figures}


a

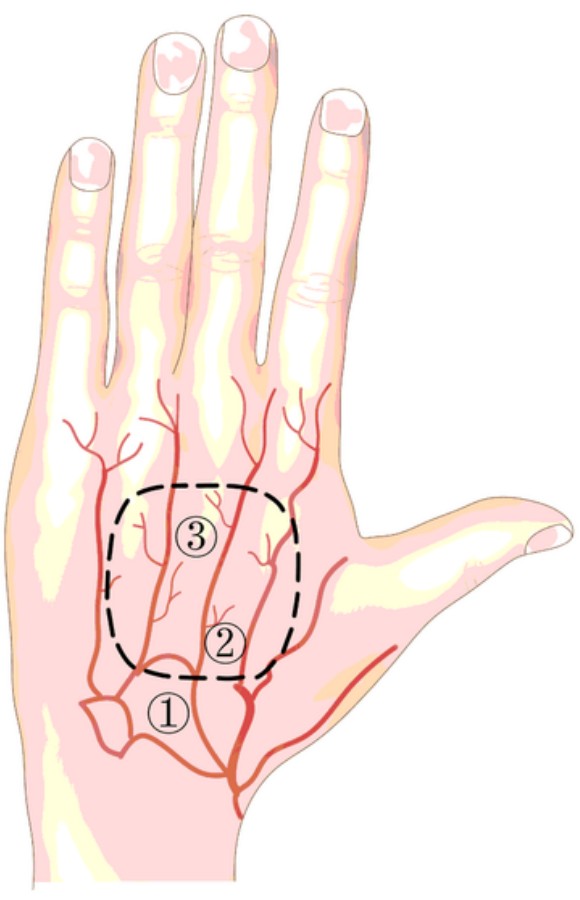

b

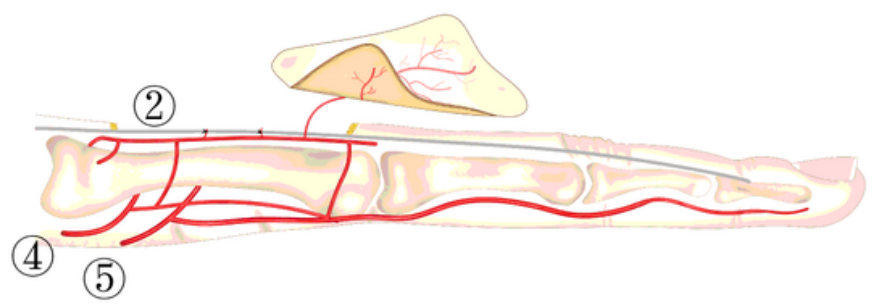

\section{Figure 1}

Anatomy of the second dorsal metacarpal artery (SDMA) and flap design. Flap design (dotted line) and incision, as seen in the front view (a) and side view (b). (1) The dorsal metacarpal arch; (2) the second dorsal metacarpal artery; (3) the transverse arterial network; (4) the deep palmar arch; and (5) the superficial palmar arch. 
a

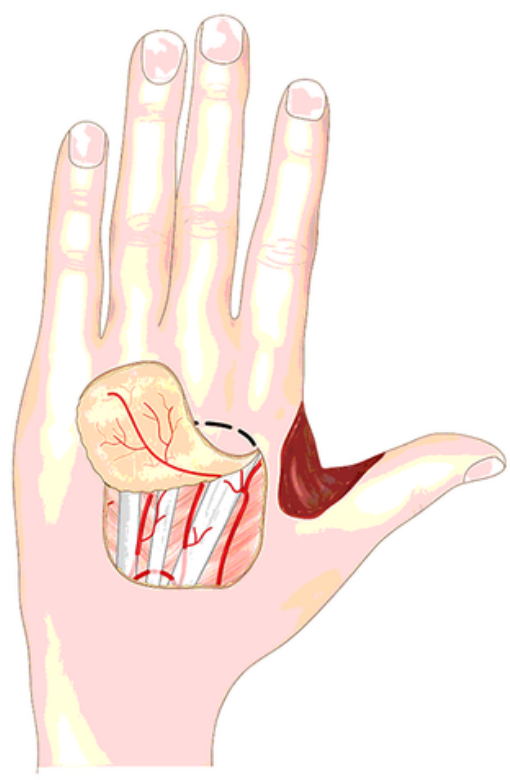

C

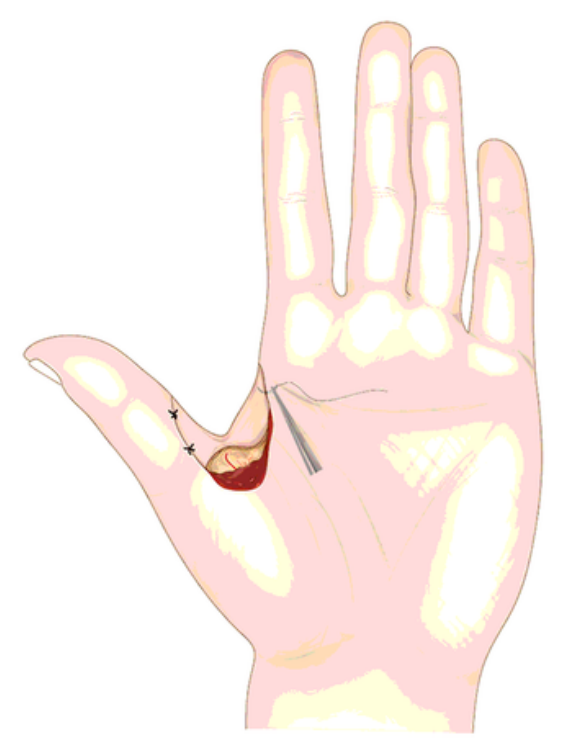

b

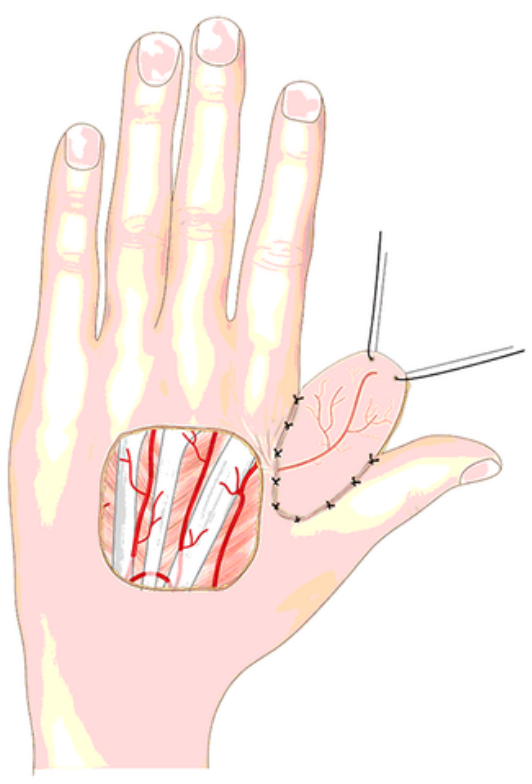

d

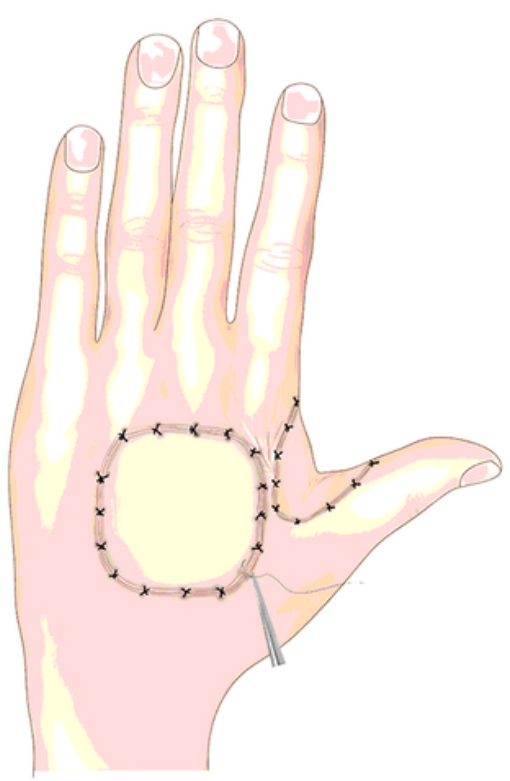

\section{Figure 2}

Design of the second dorsal metacarpal artery (SDMA) cutaneous flap. (a) The flap is raised in a proximalto-distal direction. (b) The SDMA flap is transferred and covered over the dorsal defect via a subcutaneous tunnel. (c) The SDMA flap is transferred and covered over the volar defect. (d) A full-thickness skin graft is transplanted at the donor site. 

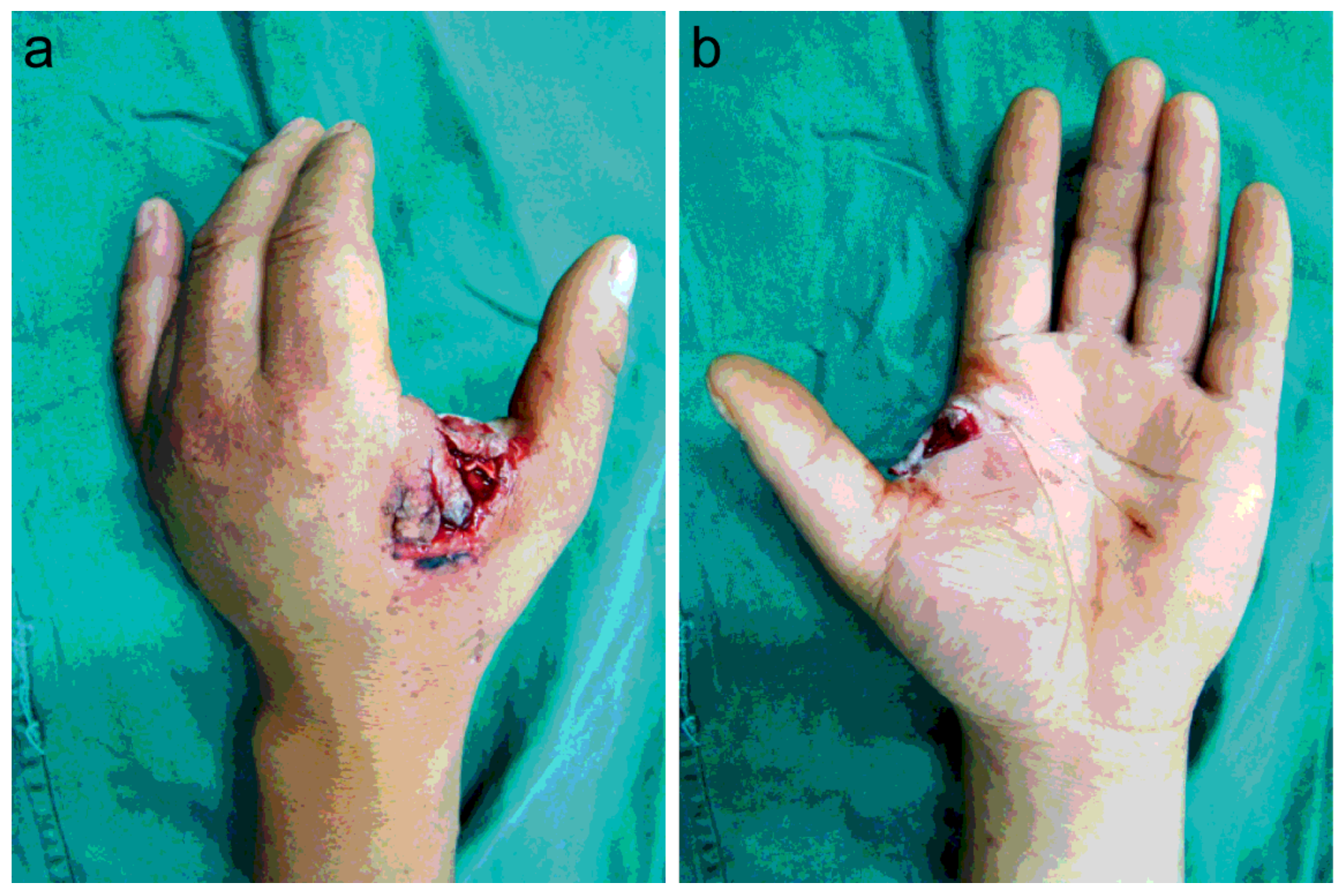

Figure 3

(a) Volar defect and (b) dorsal defect. 

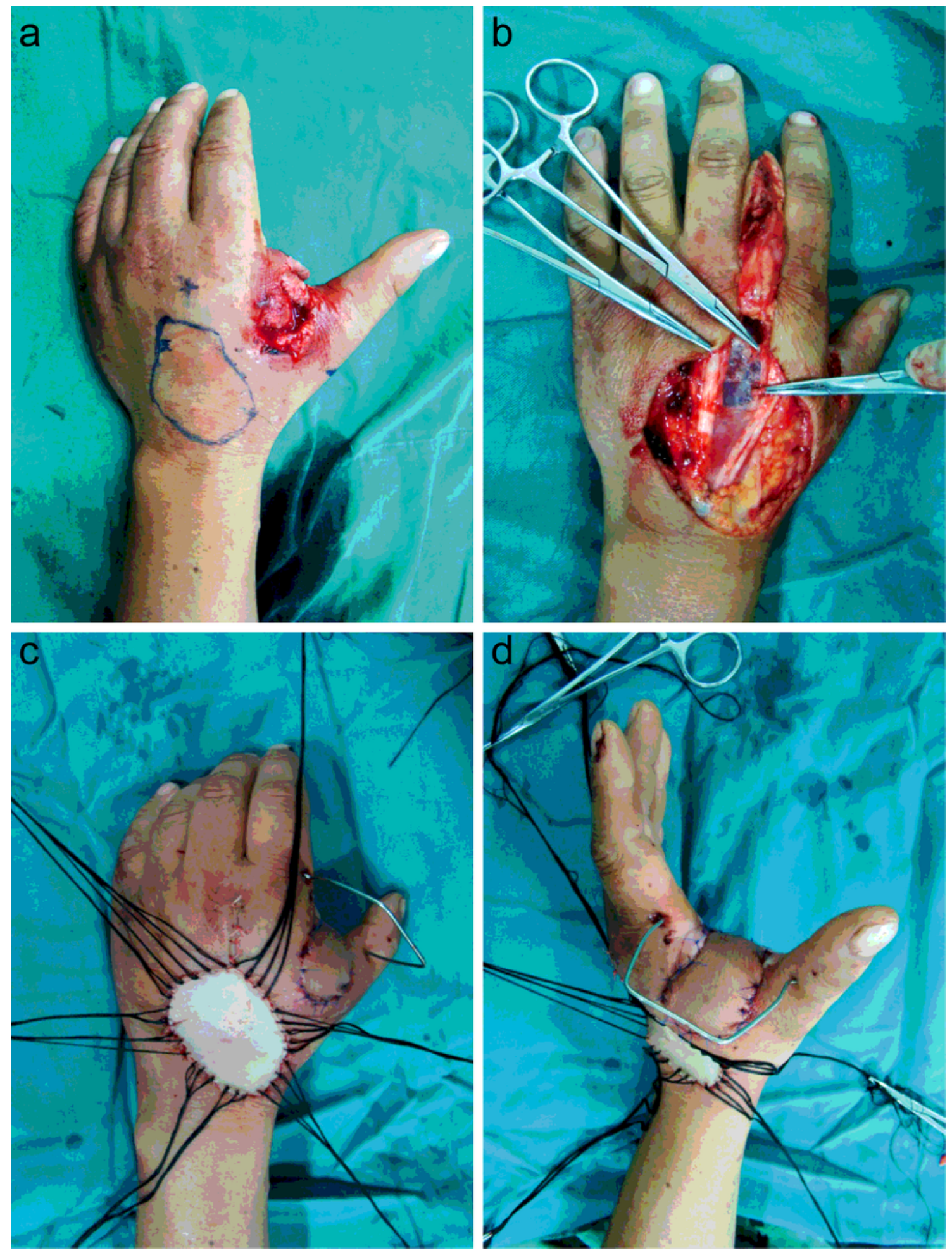

\section{Figure 4}

(a) Flap design. (b) Flap harvesting is complete. (c) The second dorsal metacarpal artery (SDMA) flap is transferred and covered over the first web-space defect via a subcutaneous tunnel. (d) A full-thickness skin graft is transplanted at the donor site. 


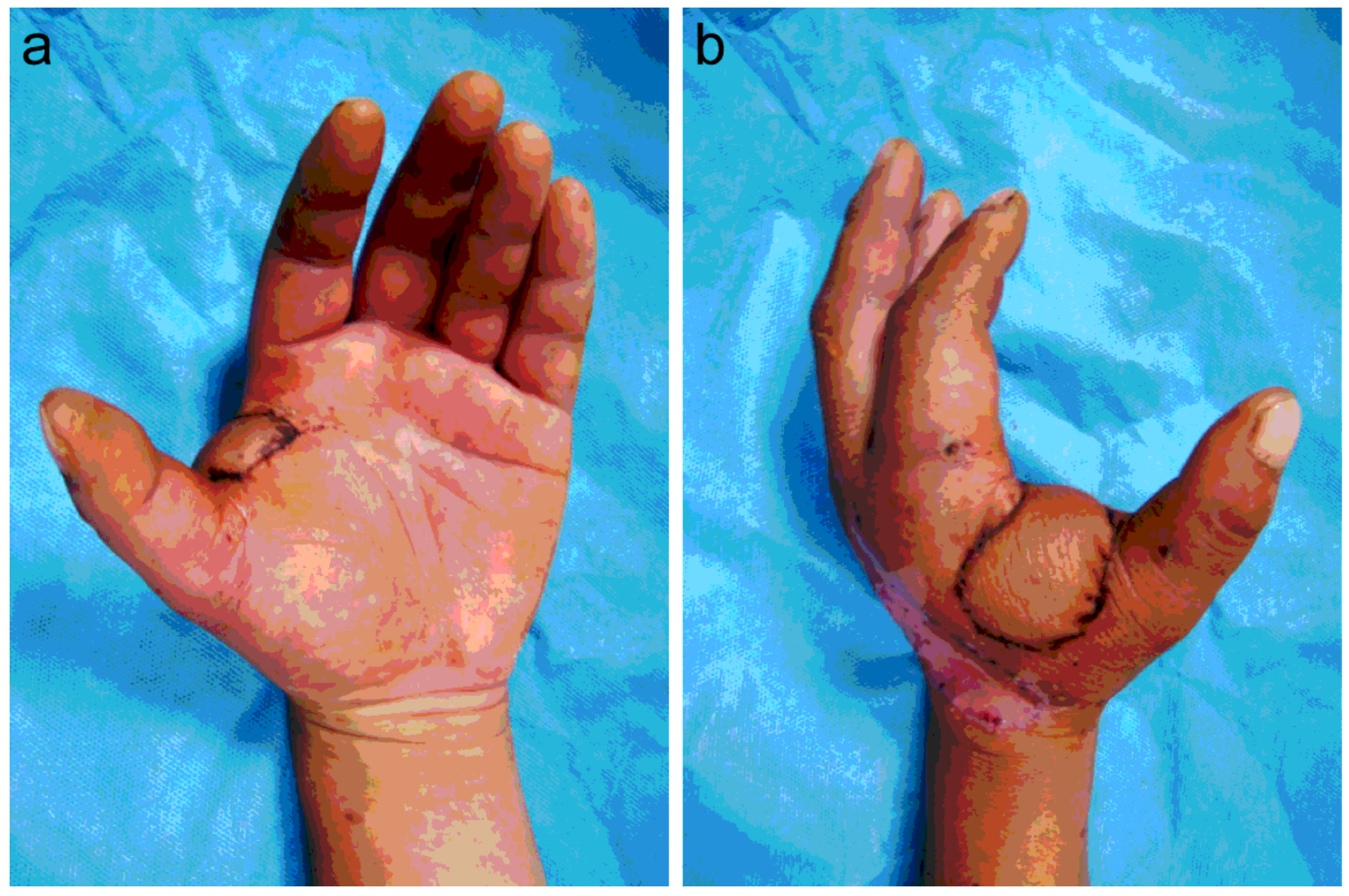

Figure 5

Postoperative 6-month follow-up examination shows a healthy appearance of the flap. 

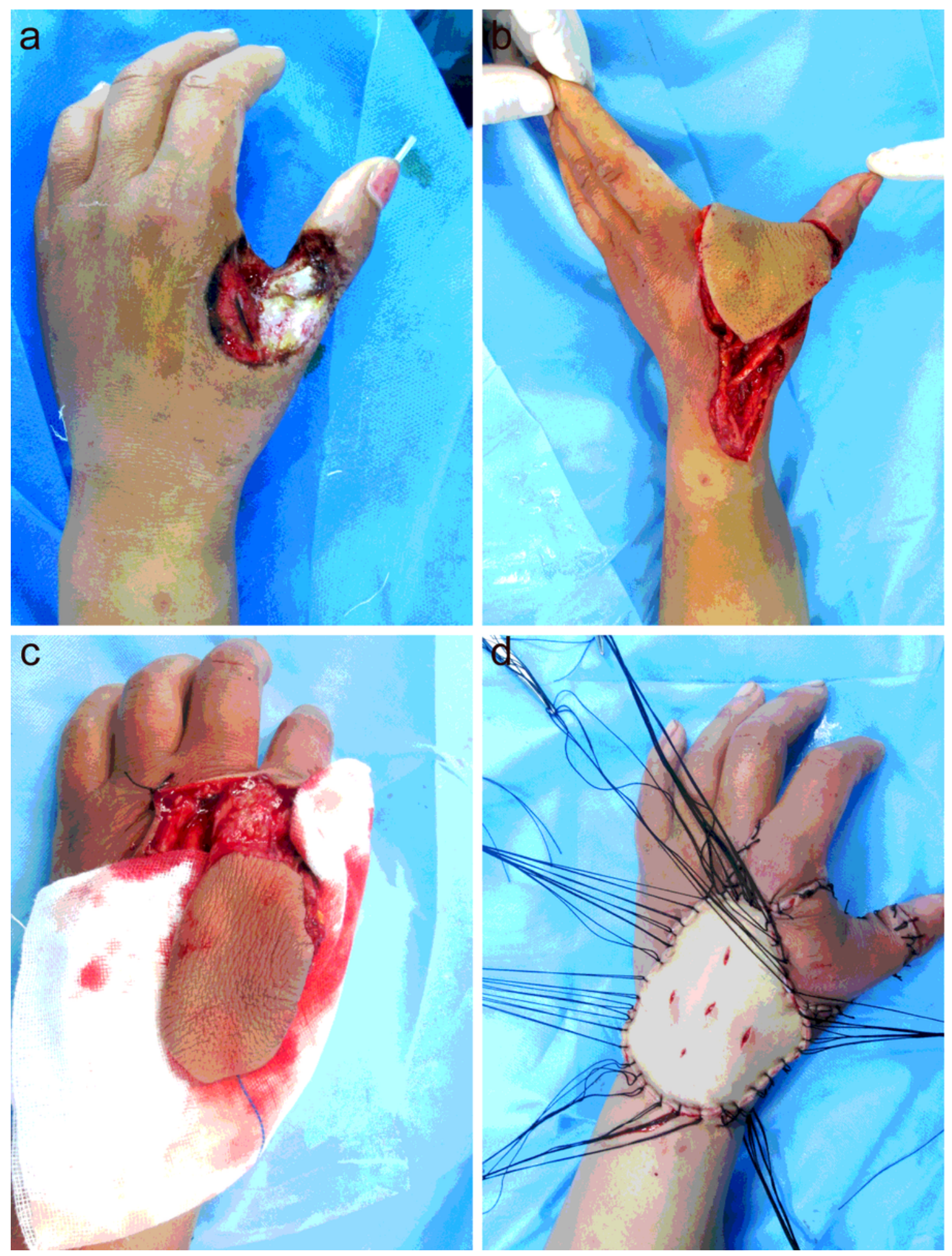

\section{Figure 6}

(a) The first web-space defect. (b) The free lateral arm flap is harvested and covered over the defect. (c) The second dorsal metacarpal artery (SDMA) flap is elevated. (d) The defect is covered with a SDMA flap. Skin from the lost flap is grafted to the dorsum of the hand. 

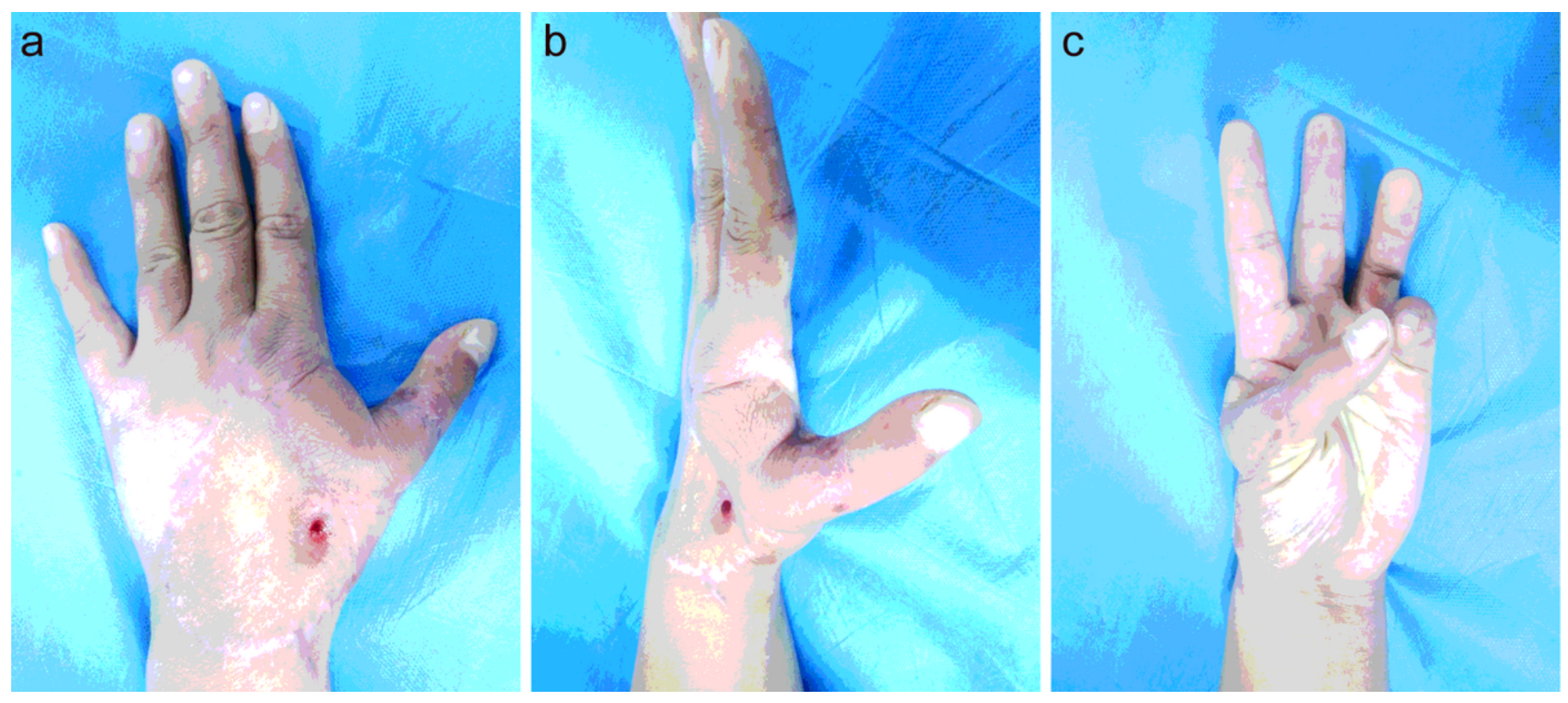

Figure 7

Results after two months postoperatively. (a) Donor sites; (b) Extension; (c) Opposition of the thumb to the little finger. 